\title{
Overlapping ion structures in the mid-altitude cusp under northward IMF: signature of dual lobe reconnection?
}

\author{
F. Pitout ${ }^{1}$, C. P. Escoubet ${ }^{2}$, M. G. G. T. Taylor ${ }^{2}$, J. Berchem ${ }^{3}$, and A. P. Walsh ${ }^{4}$ \\ ${ }^{1}$ Institut de Recherche en Astrophysique et Planétologie, UMR5277, CNRS/UPS, 9 avenue du Colonel Roche, BP 44346, \\ 31028 Toulouse cedex 4, France \\ ${ }^{2}$ European Space Agency, Keplerlaan 1, 2201 AZ, Noordwijk, The Netherlands \\ ${ }^{3}$ University of California Los Angeles, Institute of Geophysics and Planetary Physics, Los Angeles, CA 90095-1567, USA \\ ${ }^{4}$ Mullard Space Science Laboratory, Dept. of Space and Climate Physics, University College London, Holmbury St. Mary, \\ Dorking, Surrey, RH5 6NT, UK
}

Correspondence to: F. Pitout (frederic.pitout@irap.omp.eu)

Received: 30 June 2011 - Revised: 20 February 2012 - Accepted: 21 February 2012 - Published: 6 March 2012

\begin{abstract}
On some rare occasions, data from the Cluster Ion Spectrometer (CIS) in the mid-altitude cusp reveal overlapping ion populations under northward interplanetary magnetic field (IMF). While the poleward part of the cusp exhibits the expected reverse dispersion due to lobe reconnection, its equatorward part shows a second ion population at higher-energy that coexists with the low energy tail of the dispersion. This second population is either dispersionless or slightly dispersed with energies increasing with increasing latitudes, indicative of lobe reconnection as well. Our analysis of a case that occurred 3 September 2002 when the IMF stayed northward for more than two hours suggests that the second population comes from the opposite hemisphere and is very likely on newly-closed field lines. We interpret this overlap of cusp populations as a clear mid-altitude signature of re-closed magnetic field lines by double lobe reconnection (reconnection in both hemispheres) under northward IMF. This interpretation is supported by modelling performed with the Cooling model and an MHD model.
\end{abstract}

Keywords. Magnetospheric physics (Magnetopause, cusp, and boundary layers; Solar wind-magnetosphere interactions)

\section{Introduction}

\subsection{Velocity filter effect and ion dispersion}

The well-known velocity filter effect that affects the magnetosheath ions injected into the magnetospheric cusps is thought to be the cause of ion dispersions observed by lowand mid-altitude satellites (Reiff et al., 1977; Burch et al., 1982). Basically, higher energy ions travel faster along convecting magnetic field lines and thus reach a given altitude first, i.e. at an earlier stage of the field line convection. The dispersion depends therefore on the distance between the reconnection site and the satellite aboard which the dispersion is recorded, and on the motion of newly-opened field lines (direction and magnitude of the convection velocity). When the IMF is southward, reconnection is expected to occur at the dayside magnetopause between the two cusps and the convection to be directed anti-sunward. The dispersion is then such that the energy of the ions detected at a given altitude decreases with increasing latitudes. In contrast, when the IMF points northward, reconnection is favoured at highlatitude, poleward of the cusps. The convection in the cusps is then sunward and the dispersions are then reversed (Burch et al., 1980) and show decreasing energies with decreasing latitudes. In absence of IMF data, the type of dispersion one observes in the ion data provides a simple and rather reliable way to find out under which IMF polarity $\left(B_{\mathrm{z}}\right.$ positive or negative) the cusp crossing occurred (e.g. Pitout et al., 2009). 


\subsection{Dual lobe reconnection}

When the IMF has a positive Z-component and small X-and Y-components (so that the cone and clock angles of the IMF are close to $90^{\circ}$ and $0^{\circ}$, respectively), reconnection may occur, simultaneously or not, in the lobes of the two hemispheres (Dungey, 1963; Cowley, 1981) leading to newlyclosed field lines on the dayside (Lockwood and Moen, 1999; Lavraud et al., 2006). The closure of two open field lines yielding an external newly-closed field line in the dayside magnetosheath, near the magnetopause, was put forward to explain the formation of a thick low-latitude boundary layer under northward IMF (Song and Russell, 1992). However, it remains unclear whether the two reconnections have to be simultaneous or if their successive occurrence may also lead to the same result (Bogdanova et al., 2005, 2008).

The signatures of newly-closed magnetic field lines formed by dual lobe reconnection are remarkably well summarised by Hu et al. (2008). Those signatures can be found in the plasma parameters either near the magnetopause (inside or outside) or in the middle altitude cusp (as presented in this paper).

Bidirectional electrons beams are observed on both sides on the magnetopause: outside the magnetosphere in the magnetosheath boundary layer (Onsager et al., 2001) and inside the magnetosphere in the LLBL. Also, the existence of a trapped plasma sheet population mixed with an accelerated magnetosheath population is thought to be a signature inside the magnetosphere.

In the cusp, reclosed magnetic field lines may be identified by the presence of downgoing oxygen ions likely outflowing from the opposite hemisphere's ionosphere (Fuselier et al., 2001), the presence of accelerated plasma ascribed to the additional acceleration at the second reconnection site, and the presence of an isotropic plasma population due to pitch-angle scattering of ions and electrons made possible by a long field line lifetime since it was reclosed (Bogdanova et al., 2005). However, as pointed out by $\mathrm{Hu}$ et al. (2008) who compared the results and diverging conclusions of Bogdanova et al. (2005) and Provan et al. (2005) about the plasma convection associated with the reclosure of open field lines, there seems to be different signatures depending on the stage of the reclosed field lines' lifetime. Likewise, they also mention that the expected IMF conditions for having dual lobe reconnection vary from one study to another. For instance, Imber et al. (2006) suggested that a very strong northward IMF with a clock angle smaller that $10^{\circ}$ (in absolute value) was required, whereas the statistical study performed by Lavraud et al. (2006) revealed cases of dual lobe reconnection while the clock angle of the prevailing IMF was as high as $\pm 40^{\circ}$.

\subsection{Overlapping ion populations in the cusp}

Nonetheless, the cusp also often exhibits more disturbed behaviours and large scale morphologies that do not fall in any of the two simple cases (dispersion or reversed dispersion). Yamauchi and Lundin (1994) identified a variety of morphologies depending on the IMF conditions. More recently, Pitout et al. (2009), while performing their statistical study of the mid-altitude cusp, noticed a peculiar morphology: on some rare occasions, the cusp exhibits an overlap of two magnetosheath ion populations under northward IMF. This feature, i.e. the overlap of ion populations in the cusp, was reported by a few authors in the past but mainly for southward IMF conditions (Trattner et al., 1998). Such overlaps were then explained in terms of a pulse of reconnection catching up with another (Lockwood, 1995) or by a pressure pulse (Xue et al., 1997).

The northward IMF case though is much less documented. There is evidence that, at times, equatorward of the cusp, a second ion dispersion with increasing energies ions with decreasing latitudes is observed. Topliss et al. (2000) have modelled those two ion populations in the cusp under prolonged northward IMF conditions, one dispersed coming from the velocity filter effect, the second at higher energies toward the equator, due to the increased contraction speed of reconnected field lines.

In this paper, we present one of those peculiar cases where two reversed dispersions overlapping each other are observed in the mid-altitude cusp by the Cluster spacecraft.

\section{Observations}

\subsection{ACE data}

On 3 September 2002, while the four Cluster spacecraft (Escoubet et al., 2001) were orbiting the Earth in the dayside magnetosphere at middle altitude in a "string of pearls" configuration, i.e. following one another, they went successively through the Southern Hemisphere's cusp. The first panel of Fig. 1 gives an overview of the prevailing IMF data during our observations and of the Cluster data between 06:20 and 08:20 UT. The first panel displays the three GSM component of the IMF measured by the MAG instrument (Smith et al., 1998) on board the ACE spacecraft (Stone et al., 1998). The data from the OMNI dataset (shifted data to the bow shock nose) have been lagged by an additional $10 \mathrm{~min}$ to account for the propagation from the bow shock to the Cluster spacecraft. We can see that the OMNI procedure failed to lag the ACE data from $~ 08: 05$ onward. The Z-component (in red) of the IMF remained around $+10 \mathrm{nT}$ during almost the whole time interval except after 07:40 UT when $B_{\mathrm{Z}}$ decreased twice down to $+5 \mathrm{nT}$ at 07:50 UT and just below $0 \mathrm{nT}$ around 08:00 UT. The two other components $\mathrm{x}$ (green) and y (blue) are rather stable until 07:15 UT: $B_{\mathrm{x}} \sim 0$ and $B_{\mathrm{y}} \sim-5 \mathrm{nT}$. After 07:15 UT, $B_{\mathrm{X}}$ starts a slow decrease and reaches $-6 \mathrm{nT}$ at 07:50 UT, while $B_{\mathrm{y}}$ slowly increases to $+4 \mathrm{nT}$ at 07:50 UT. Like for $B_{\mathrm{z}}$, the interval 07:50-08:05 UT in somewhat more disturbed: $B_{\mathrm{x}}$ varies around $-5 \mathrm{nT}$ and $B_{\mathrm{y}}$ peaks at $+9 \mathrm{nT}$ 


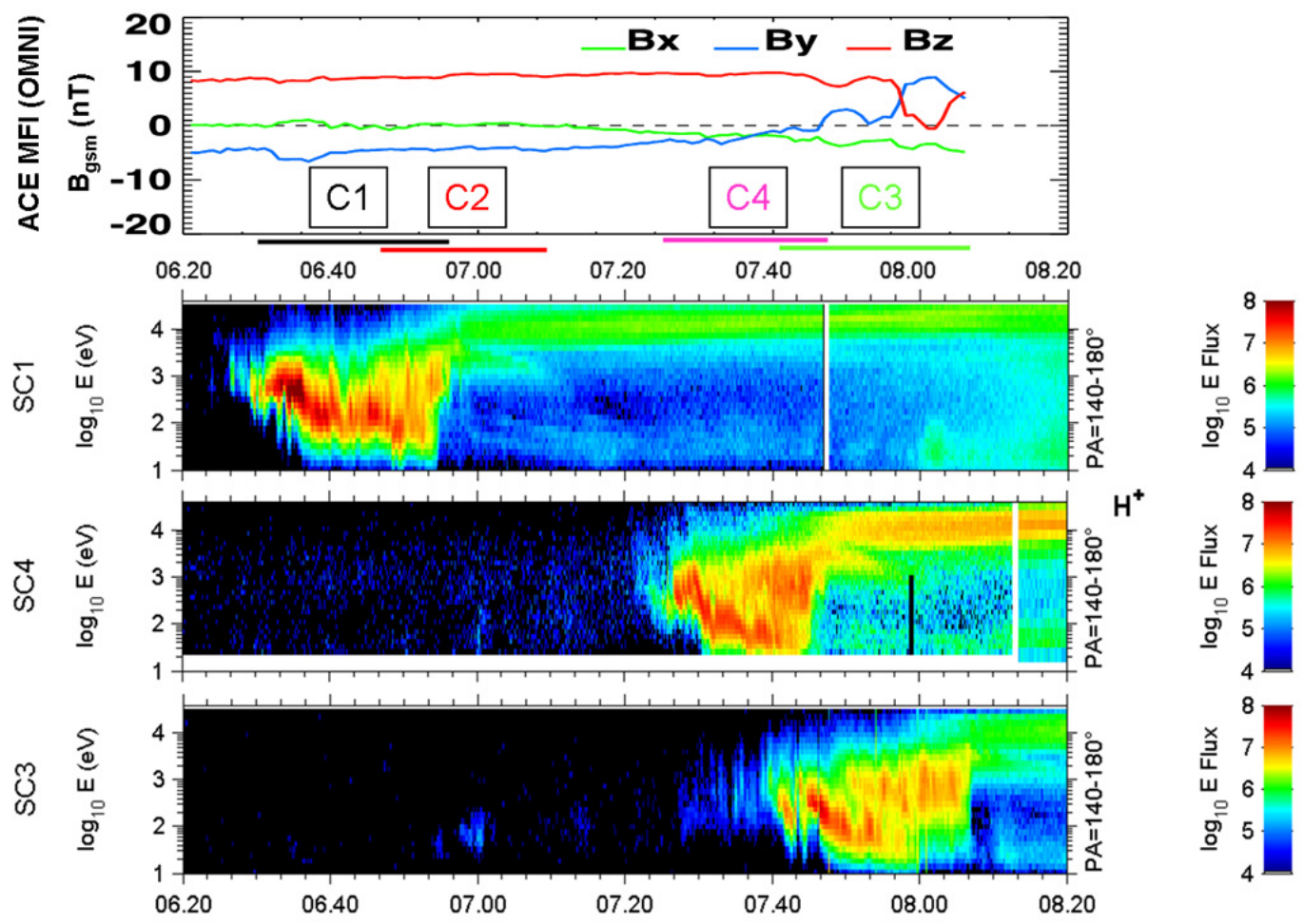

Fig. 1. From top to bottom, the 3 components of the IMF measured by ACE (shifted by 65 min to take into account the propagation time) and energy-time ion spectrograms from Cluster-CIS on board spacecraft 1, 4 and 3.

around 08:00 UT. From 08:05 UT, the values of all components return to a stable regime: $B_{\mathrm{x}} \sim-3 \mathrm{nT}, B_{\mathrm{y}} \sim-1 \mathrm{nT}$, and $B_{\mathrm{Z}} \sim+10 \mathrm{nT}$.

\subsection{Cluster-CIS data}

The three last panels of Fig. 1 show ion spectrograms of precipitating particles (pitch-angle between 140 and $180^{\circ}$ ) measured by CIS (Rème et al., 2001) instrument on board spacecraft (SC) 1, 4 and 3 (SC2 ion data are not available). The periods of high flux of $\sim \mathrm{keV}$ ions are characteristic for the polar cusp: magnetosheath ions are detected. SC1, SC4 and SC3 record successively reversed ion dispersions starting respectively at 06:30 UT, 07:30 UT and 07:40 UT, typical for northward IMF (Bosqued et al., 1985).

Chronologically, SC1 is the first spacecraft of the Cluster fleet to cross the cusp. The ion spectrogram recorded by its CIS instrument (2nd panel), shows one reversed dispersion starting at $\sim 06: 30$ UT, followed from 06:40 UT by a ion population at lower energies, which does not exhibit a clear large-scale dispersion. Then SC4 entered the cusp at $\sim 07: 26$ UT (third panel). Its CIS spectrometer also records a reversed dispersion for about $10 \mathrm{~min}$. An interesting feature should draw the reader's attention: from $\sim 07: 35 \mathrm{UT}$, a second ion population appears at higher energy. Given the differential energy fluxes $\left(\sim 10^{7} \mathrm{eV} \mathrm{sr}^{-1} \mathrm{~cm}^{-2} \mathrm{~s}^{-1}\right)$ and energy range $(\sim \mathrm{keV})$ of this population, there is no doubt that it is also of magnetosheath origin. SC3 is the last spacecraft to reach the cusp at $\sim 07: 40$ UT (bottom panel). The CIS instrument aboard also records a reversed dispersion of magnetosheath ions and, starting at 07:50 UT, a second population at higher energy that overlaps with the first one. One should note that in this data set, the two ion populations are more detached and second dispersion is more extended in latitude compared to SC4 data.

Figure 2 shows a velocity distribution function measured by SC4 at 07:38 UT, when two overlapping ion populations are recorded. The top panel shows the colour-coded energy flux as a function of the velocity components perpendicular and parallel to the local magnetic field. We clearly see in dark red two high-flux populations: one rather isotropic with an anti-parallel population of $-100 \mathrm{~km} \mathrm{~s}^{-1}$ and a parallel population of $250 \mathrm{~km} \mathrm{~s}^{-1}$ (as expected on old reconnected field lines: outgoing/reflected magnetosheath ions have higher energies than down-going ions), and another seen mainly in the anti-parallel direction (precipitating ions) at about $-400 \mathrm{~km} \mathrm{~s}^{-1}$. The bottom panel shows the same distribution function but in the plane perpendicular to the magnetic field. 
CIS-CODIF TANGO (SC 4) 03/Sep/2002 07:38:32.993
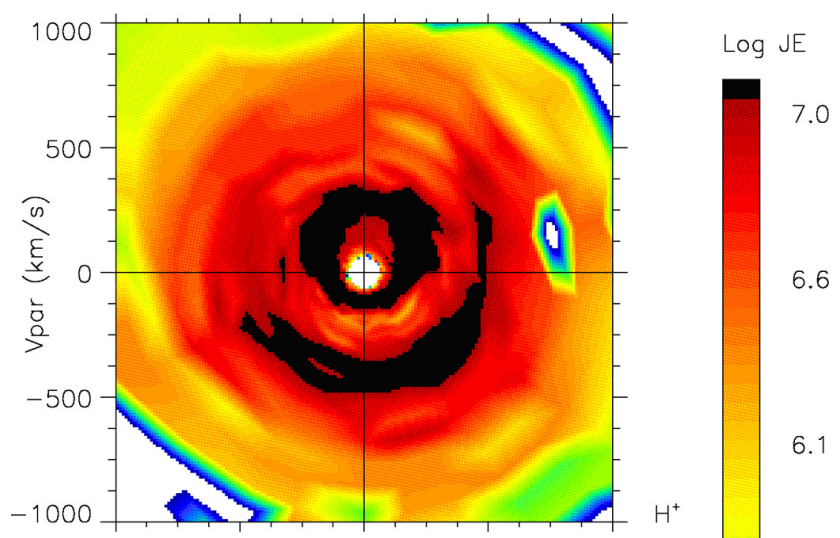

6.6

Vperp1 $(\mathrm{km} / \mathrm{s})$

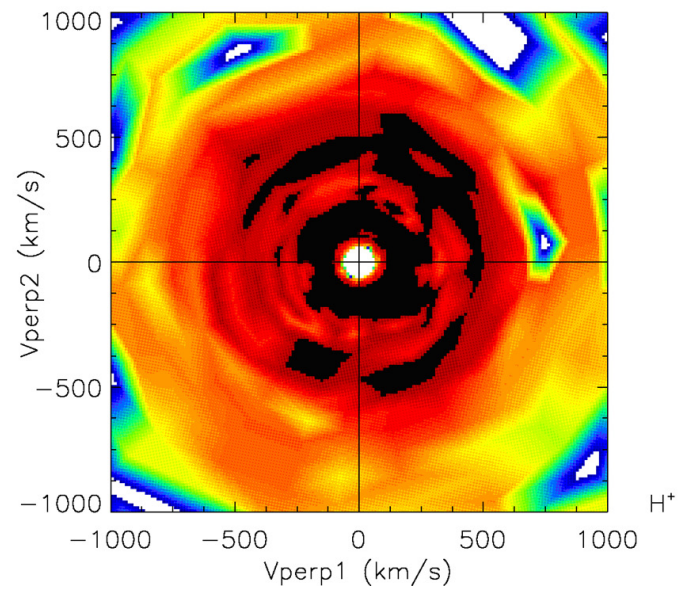

Fig. 2. Cuts of the ion distribution function recorded by CODIF on SC4 at 07:38:33 UT in a plane parallel to the magnetic field (top) and perpendicular to the magnetic field (bottom).

To have a more precise and detailed view of the plasma properties in the regions of interest, we have plotted in the Figs. 3, 4, and 5 data from CIS-CODIF analyzers onboard the Cluster SC1, 4 and 3, respectively. (For SC3, the data come partly from the CIS-HIA detector; see below). Each figure shows from top to bottom the H+ density, the 3 GSM components of the $\mathrm{H}+$ velocity perpendicular and parallel to the magnetic field, an energy-time $\mathrm{H}+$ spectrogram, and two pitch angle-time spectrograms for $\mathrm{H}+$ whose energy is greater and lower to $400 \mathrm{eV}$, as functions of universal time.

When SC1 first encounters the southern polar cusp, the IMF is then $(0,-5,+10) \mathrm{nT}$ in GSM. Slightly before 06:30 UT, CODIF starts to detect higher den-

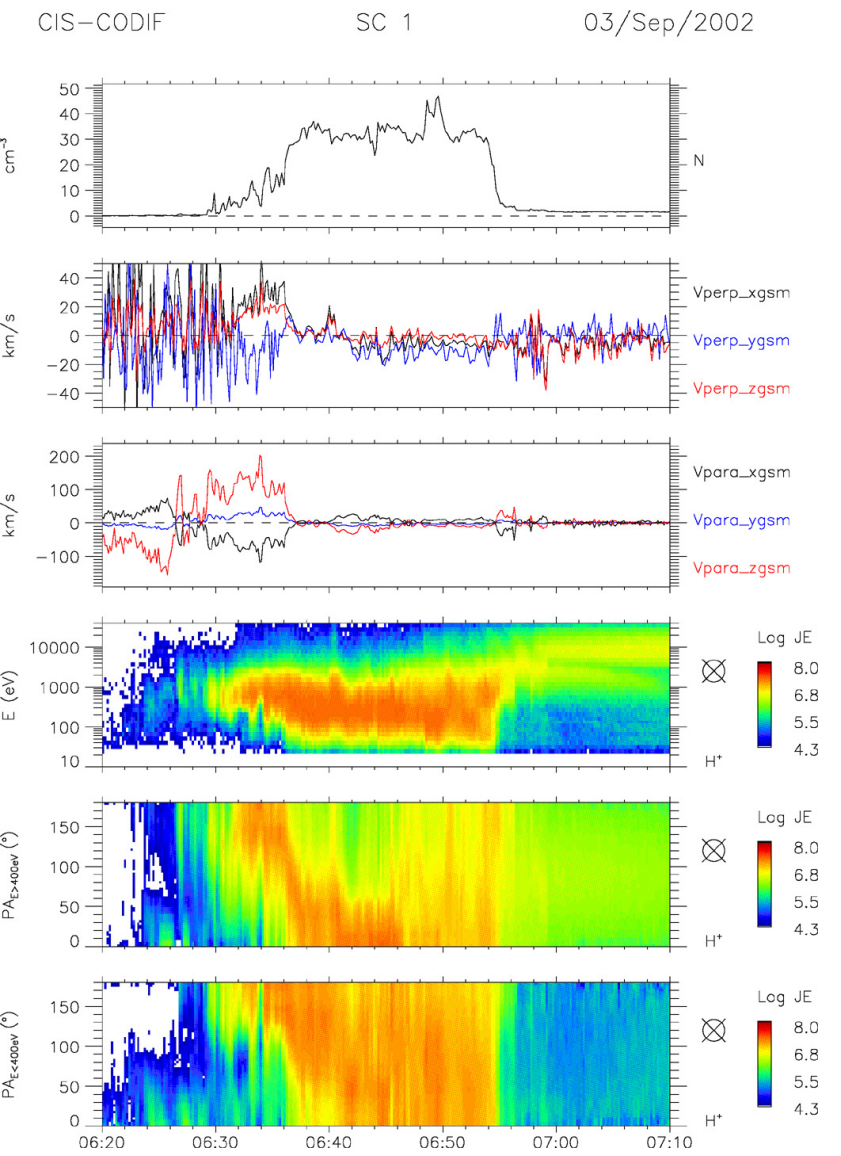

Fig. 3. CIS-CODIF data from SC1 with from top to bottom: the $\mathrm{H}+$ density, the $3 \mathrm{GSM}$ components of $\mathrm{H}+$ velocity perpendicular and parallel to $B$, an energy-time $\mathrm{H}+$ spectrogram, and two pitch angle-time spectrograms for $\mathrm{H}+$ with $E<400 \mathrm{eV}$ and $E>400 \mathrm{eV}$, as functions of universal time.

sity plasma (10-20 $\left.\mathrm{cm}^{-3}\right)$ with high fluxes exceeding $10^{7} \mathrm{eV} \mathrm{sr}^{-1} \mathrm{~cm}^{-2} \mathrm{~s}^{-1} \mathrm{eV}^{-1}$ of $\sim \mathrm{keV}$ ions. The convection plasma velocity (around $50 \mathrm{~km} \mathrm{~s}^{-1}$ ) associated to downgoing protons indicate that $\mathrm{SC} 1$ flies through open magnetic field lines reconnected in the Southern Hemisphere. The positive $V_{\mathrm{x}}$ confirms that these open field lines convect sunward. The features of open field lines (high plasma velocity, high density, and precipitating protons) stop at around 06:36 UT. Then the plasma becomes even denser (up to $\sim 35 \mathrm{~cm}^{-3}$ ) and its convection velocity drops suddenly to very low values. Also from this time on, lower-energy protons are observed at all pitch angles while higher-energy protons are seen mainly in the parallel direction (up-going). The spacecraft is flying through this dense region until about 06:55 UT. It has to be noted that from $\sim 06: 45$ UT to 06:55 UT, high-energy (few $\mathrm{keV}$ ) and isotropic ions are again recorded and that after 06:55 UT, when high-energy plasma sheet ions are detected, CIS still detects a $2 \mathrm{keV}$ ion population until 07:10 UT.

At 07:26UT, SC4 (Fig. 4) enters a region of high fluxes of $\sim \mathrm{keV}$ ions. The ion signatures resemble those recorded 


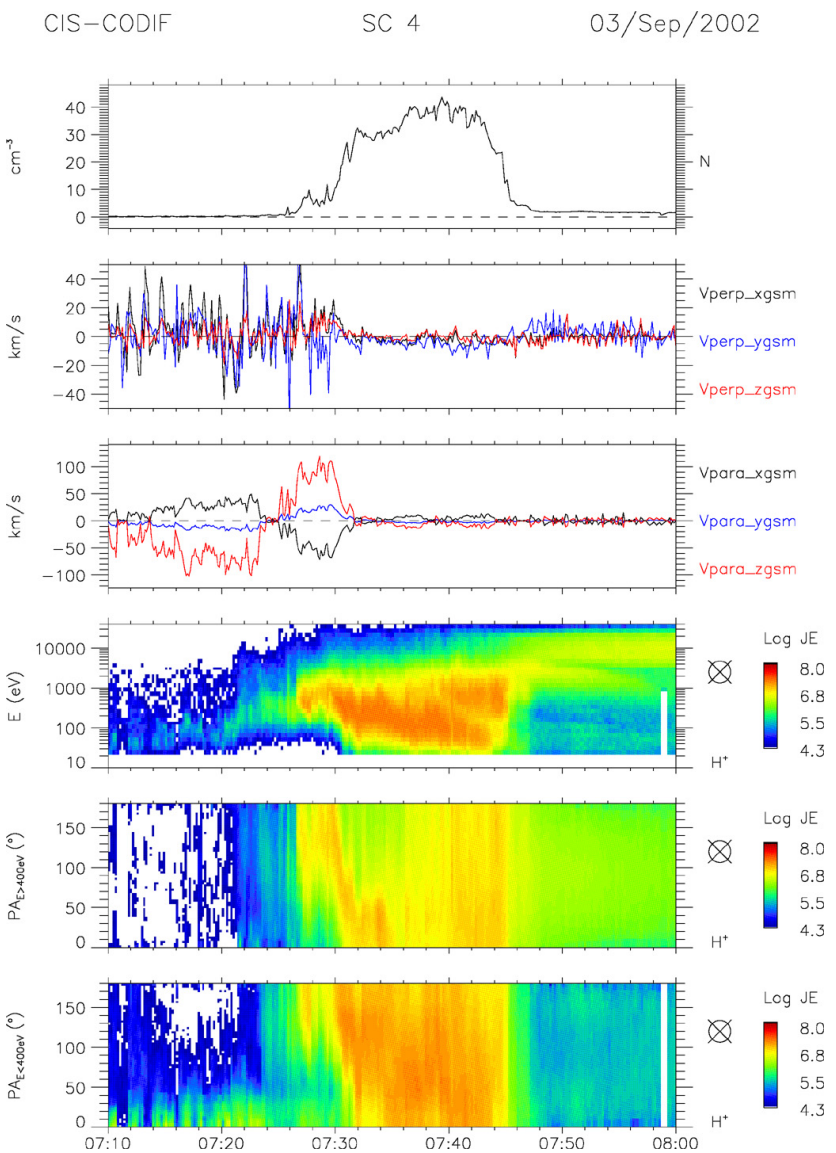

Fig. 4. Same as Fig. 3 for SC4.

by SC1. The clearly dispersed part of the ion population (between 07:26 and 07:32 UT) is associated with moderate increase of the ion density up to $10 \mathrm{~cm}^{-3}$, a sunward convection flow, and precipitating protons (positive $\mathrm{Z}$ component of the parallel velocity and, equivalently, pitch angles close to $180^{\circ}$ ). Then, between 07:32 UT and 07:45 UT (when high-energy plasma sheet ions are detected) protons are more isotropic, filling all pitch angles. From 07:40 UT, a second area of high ion flux (dark red) is recorded just below $1 \mathrm{keV}$. One can again observe a $\mathrm{keV}$ ion population overlapping with plasma sheet ions until 07:58 UT.

SC3 is the last satellite to fly through the region of interest. We have displayed in Fig. 5 data recorded by its CIS instrument but in a slightly different way. Since the CODIF sensor has always had degraded performance and that indeed the moments (not shown) looked very noisy, we have plotted in the two top panels the ion density and velocity perpendicular to the magnetic field (as for SC1 and SC4) recorded by the HIA sensor instead. Similarly to our previous observations, the ion density increases to moderate values of about $10 \mathrm{~cm}^{-3}$ at the beginning of the cusp encounter, here just after 07:40 UT, before ramping up to values between 30 and $40 \mathrm{~cm}^{-3}$. The plasma flow perpendicular to $B$ is pre-

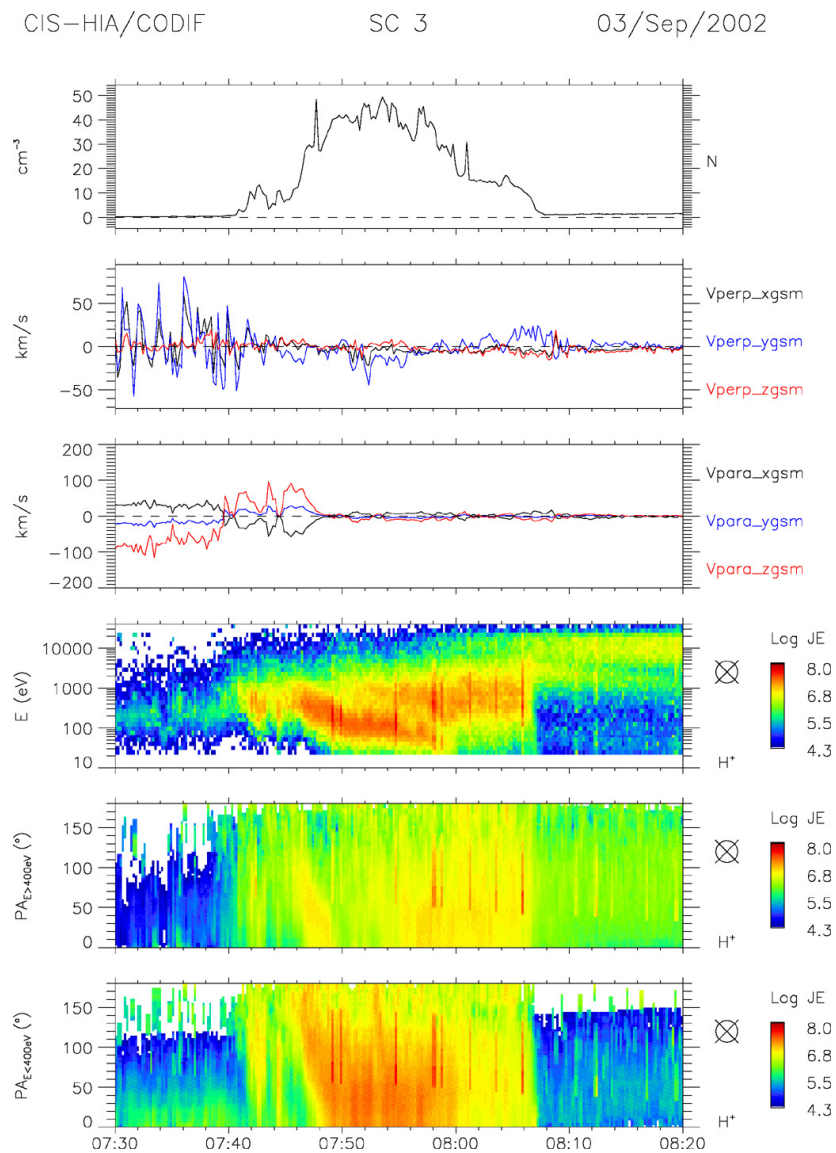

Fig. 5. Same as Fig. 3 for SC3 except that the moments come from the CIS-HIA sensor.

dominantly weekly $\left(\sim+10 \mathrm{~km} \mathrm{~s}^{-1}\right)$ sunward at the beginning of the crossing (until 07:48 UT) and then, keeps globally a null or weak antisunward direction throughout the rest of the time interval presented. This weak plasma velocity is thus recorded when the two overlapping ion dispersions are observed, between 07:50 and 08:00 UT. Right after these two dispersions are observed, there is a region, which is not detected by CIS onboard SC1 and 4 that is observed between 08:00 and 08:07 UT. This ion population exhibits no large scale energy dispersion and has energies between $100 \mathrm{eV}$ and $\sim 3 \mathrm{keV}$. The detection of this population corresponds to a weaker ion density $\left(\sim 15 \mathrm{~cm}^{-3}\right)$ and westward convection.

\subsection{Cluster-PEACE data}

We have used electron data from the PEACE instrument (Johnstone et al., 1997) onboard SC1, and SC3 (PEACE data from SC4 not available). Figures 6 and 7 both show pitch angle-time spectrograms for several energy bins between $2.8 \mathrm{eV}$ and $1.1 \mathrm{keV}$ from the LEEA sensor. The pitch angle distribution is indicated for each energy channel, ranging from $0^{\circ}$ at the bottom to $180^{\circ}$ at the top of each panel. 


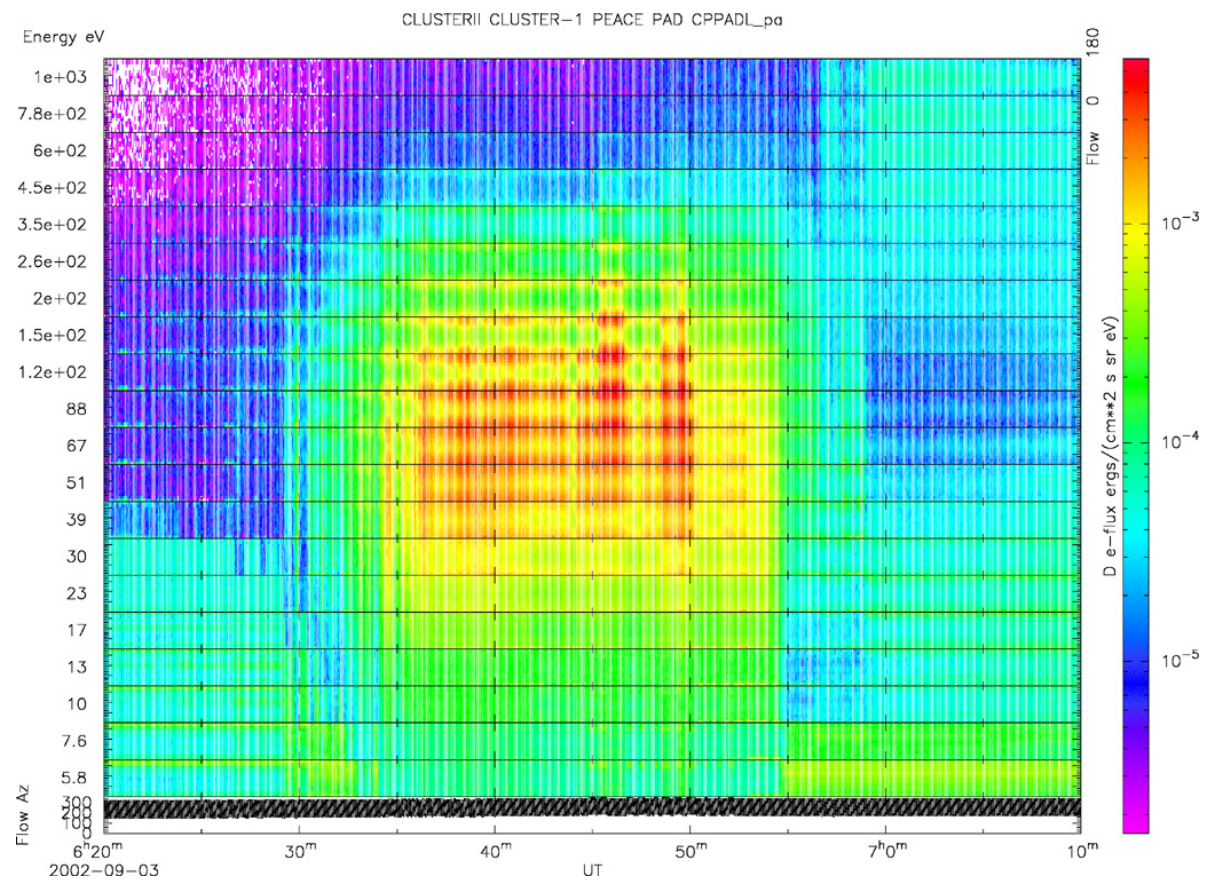

Fig. 6. PEACE-LEEA electron pitch angle-time spectrogram from SC1 showing, for each energy bin, the colour-coded energy flux.

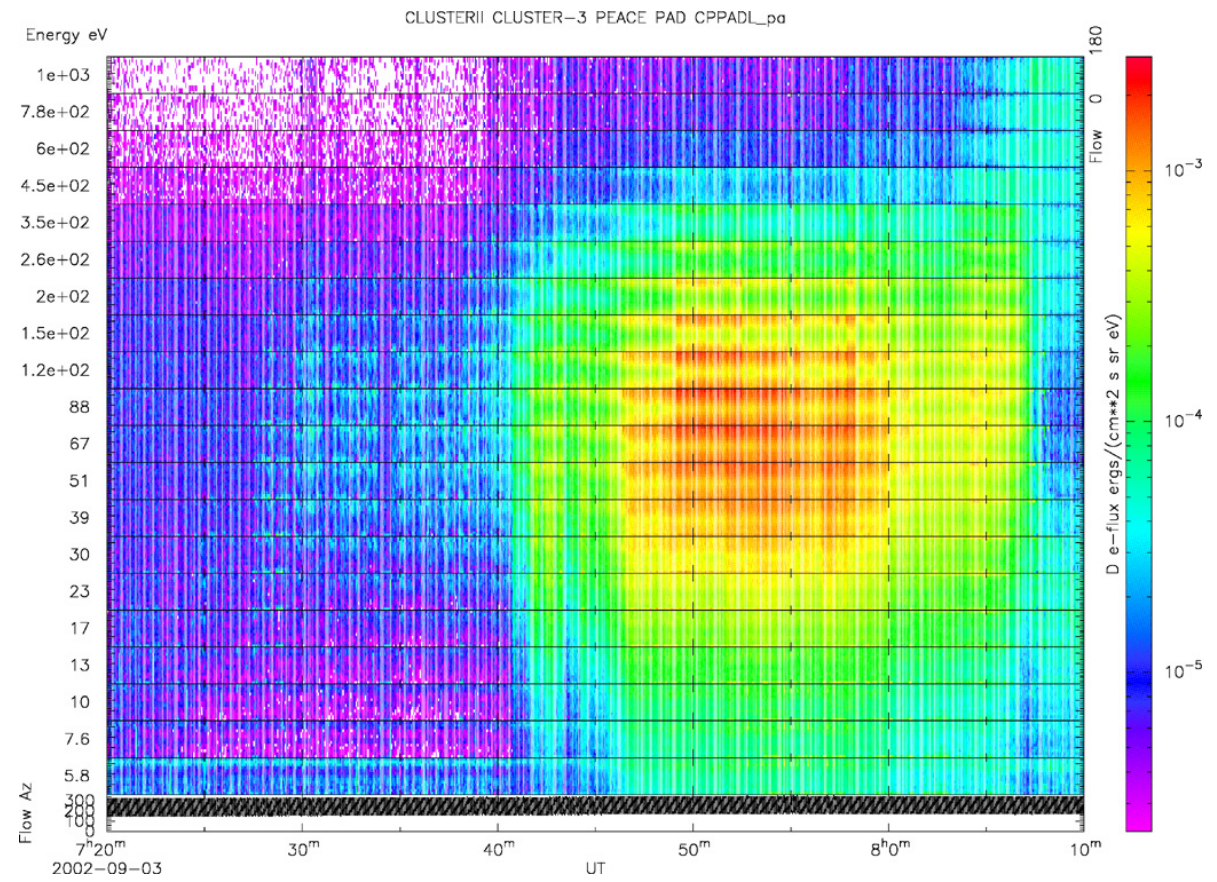

Fig. 7. Same as Fig. 6 for SC3.

When entering the cusp, electron sensors onboard all spacecraft detect as expected high fluxes of $\sim 100 \mathrm{eV}$ electrons in the directions parallel and anti-parallel to the magnetic field. The detections start at 06:30 UT for SC1 and shortly after 07:40 UT for SC3, which is consistent with the timing given by the ion spectrometer (previous section).
SC1 observes an increase of flux of the electrons in the range $\sim 40-400 \mathrm{eV}$ at $\sim 06: 30 \mathrm{UT}$, with electrons aligned with the field but with anti-parallel fluxes dominant, indicative of magnetosheath electrons injected into the cusp. Rapidly, from 06:35 UT, the electrons become more bidirectional, indicative of electrons being injected at a reconnection 
site (anti-parallel) and electrons bouncing at low altitude (parallel). At 06:55 UT, the energy fluxes drops at all energies and $\mathrm{keV}$ electrons start to be detected around 07:57 UT, indicative of dayside plasma sheet.

The SC3 PEACE data, from 07:40 UT until 07:47 UT show high fluxes of field aligned electrons, with fluxes dominating in the anti-parallel direction (into the cusp). From $\sim 07: 47$ UT onward, the fluxes become more balanced in the parallel and antiparallel direction, which is clearly visible in energy range 39-220 eV. (1-D cuts of the electron distribution functions, not shown, exhibit this tendency as well.) We note that this is also accompanied by the appearance of more energetic electrons (enhanced flues in 200$300 \mathrm{eV}$ ). After 07:58 UT there are sporadic appearances of 400-1000 eV electrons. From 08:00 UT to 08:03 UT, electron energy fluxes decrease significantly while bi-directional electrons continue to be observed. Finally, between $\sim 08: 03$ and 08:07 UT (when the dayside plasma sheet is encountered, indicated by the appearance of $1 \mathrm{keV}$ electrons), electrons with energies $\sim 39-350 \mathrm{eV}$ are enhanced anti-parallel to the magnetic field and one can see a dispersion of the lower energy cut-off with energy increasing with time (i.e. decreasing with latitude). This could be indicative of injected electrons through dayside magnetic reconnection and the initiation of a low latitude boundary layer structure (lower fluxes of electrons with energies between magnetosheath and magnetospheric).

\section{Interpretation and discussion}

\subsection{Distances to injection points}

At first glance, the slopes of the two dispersions recorded by SC3 (or SC4) are different, indicating that the points of injection where the two ion populations originate from are not at the same distance from the satellite (or that the convection velocity has changed). Moreover, back to distribution function in Fig. 2, the population at lower energies is presumed to come from a closer injection site but was injected earlier because both precipitating and reflected ions are recorded. On the other hand, the second population at high energies is mainly seen as precipitating particles. These ions have probably not had the time to be reflected at this stage.

We have used the well-known time-of-flight effect (Rosenbauer et al., 1975) and lower cut-off energy of the cusp ions (Lockwood and Smith, 1994; Lockwood, 1997) to estimate the travel distance along the magnetic field lines between the satellite and the reconnection sites. The energy $E_{\mathrm{i}}$ of a given zero-pitch angle ion of mass $m$ as a function of the distance to the reconnection site $D$ and the time of flight $t_{\mathrm{i}}-t_{0}$, is given by Lockwood $(1995,1997)$ :

$$
E_{\mathrm{i}}=\frac{m}{2}\left(\frac{D}{t_{\mathrm{i}}-t_{0}}\right)^{2}
$$

By taking two points a two different energies or velocities (noting that $E_{\mathrm{i}}=1 / 2 m v_{\mathrm{i}}^{2}$ ), the distance to the reconnection point or line is then given by the simple relation:

$D=\frac{\left(t_{2}-t_{1}\right)}{\frac{1}{V_{2}}-\frac{1}{V_{1}}}$

In a $1 / V$-time spectrogram (where $V$ is the velocity of precipitating ions), the slope of the dispersion gives us almost directly the distance to the reconnection site.

Using ion data from SC3 between 07:44 and 07:50 UT for the first dispersion (the polewardmost one), and between 07:52 and 07:59 UT for the second dispersion, we have found travel distances of $9 R_{\mathrm{E}}$ and $27 R_{\mathrm{E}}$ respectively. Furthermore, we see that the poleward edges of the two dispersions are temporally separated by $\sim 6 \mathrm{~min}$. Let us consider two protons whose energy is $1 \mathrm{keV}$ and pitch-angle $0^{\circ}$ and being injected at respectively 9 and $27 R_{\mathrm{E}}$. If we estimate the time delay between the arrivals at Cluster of these two protons coming from their respective injection point, we find $\sim 7 \mathrm{~min}$. This delay is in good agreement with the observed time delay of 6 min. We should emphasize that this calculation is obviously independent of the actual locations of the two injection sites.

\subsection{On the origins of the two dispersions}

Regarding the first dispersion, $9 R_{\mathrm{E}}$ between the injection point and Cluster correspond to an injection point in the Southern Hemisphere lobe, close to the spacecraft. For the second dispersion, we have a priori two scenarios: either the magnetosheath ions have been injected in the same lobe as the first population, i.e. in the Southern Hemisphere, or they have been injected in the Northern Hemisphere's lobe. If one field line of the southern lobe gets reconnected to the IMF in the Southern Hemisphere and this same field line reconnects with a field line of the northern lobe, we obtain a newlyclosed field line on which coexist two ion populations that have been injected, one in each hemisphere.

We should add that the modelling by Topliss et al. (2000) that explains the high energy part of the equatorward boundary of the cusp under northward IMF does not explain our observations of two overlapping reversed ion dispersions because the dispersion predicted by their modelling (increasing energy with decreasing latitude) is not the one observed here. However, it may well explain the high-energy ions $(\sim 2 \mathrm{keV})$ found equatorward of the cusp in the data of all satellites. Moreover, a distinct population but not dispersed, is observed as the continuation of the main cusp ion population as modelled by the same authors. One should note that this $\sim \mathrm{keV}$ ion population persists for a while and overlaps with highenergy dayside plasma sheet ions. 

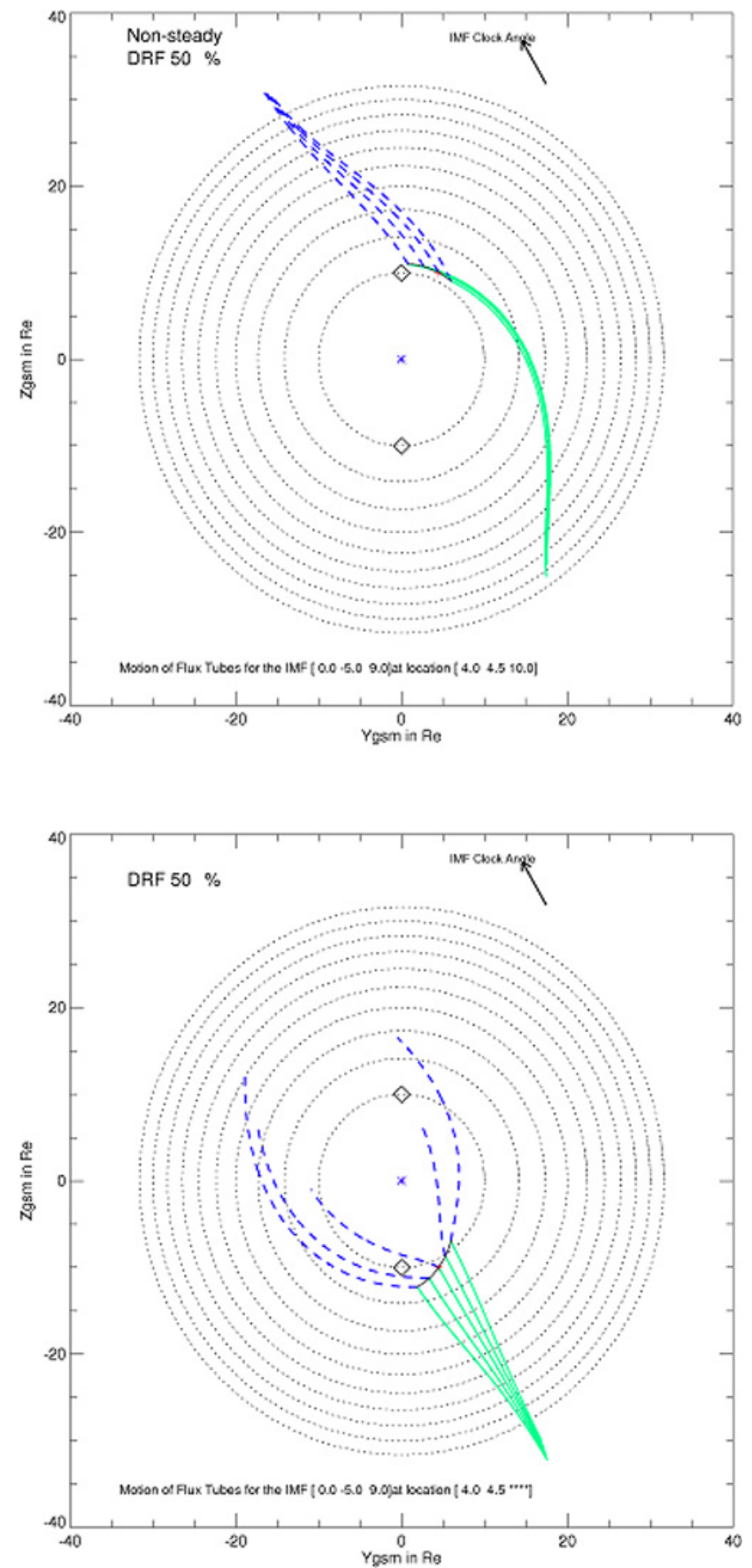

Fig. 8. Output of the Cooling model for a IMF of $(0,5,9) n T$ in GSM, corresponding to the prevailing IMF when SC1 crosses he cusp, and for a reconnection site poleward of the northern cusp (top) and poleward of the southern cusp (bottom). The blue dashed and green solid lines show the path of newly-reconnected field lines from the X-line (black solid lines).

\subsection{Signatures of dual lobe reconnection}

If our hypothesis is correct, several typical signatures in the mid-altitude cusp plasma parameters would indicate that field lines reclosed by dual lobe reconnection are observed. These signatures, some of which are summarized by $\mathrm{Hu}$ et al. (2008), are the following:

- Increase in the ion density: new closed field line eventually form the LLBL under northward IMF ad we know that under these conditions, the LLBL becomes thick and dense (Song and Russell, 1993; Bogdanova et al., $2005,2008)$. In our case, we do observe a region denser than the cusp equatorward of the latter with densities of the order of $40 \mathrm{~cm}^{-3}$.

- Slow convection or even stagnant plasma. We clearly have almost stagnant convection flows in our data. There are observed by $\mathrm{SC} 1$ after the ion dispersion and by $\mathrm{SC} 4$ and $\mathrm{SC} 3$ when the two overlapping ion dispersion are observed. Although stagnant flows do not seem to occur systematically during dual lobe reconnection (Provan et al., 2005), it appears to be recurring signature (Bogdanova et al., 2005).

- No uni-directional electron distributions, but instead bidirectional electron beams with comparable fluxes (Fuselier et al., 1997). This is clearly observed by SC3 while the two overlapping populations are recorded. $\mathrm{Bi}$ directional electrons (with very balanced fluxes at all energies) have been used previously used to indicate existence of a closed field line (Phan et al., 2005). However, such cases are usually in the LLBL regions, between both high latitude reconnection sites. In the current case, the spacecraft are located between the reconnection regions and the ionosphere, and hence bidirectionality would be driven purely by injection from the reconnection region and reflection by the ionosphere. We do observe bi-directional electrons with equivalent fluxes 07:47 UT. Also, enhanced fluxes could be an indication of an additional source population, from a second reconnection site for example.

- More isotropic plasma. As previously open field lines reclose, pitch angle scattering come into play and the plasma tends to become more isotropic ( $\mathrm{Hu}$ et al., 2008). We do have indication of this in CIS data. Protons populate all pitch-angle during the time intervals when the overlapping dispersions are recorded.

- Bidirectional oxygen ions (Fuselier et al., 2001). This signature has not been detected in our data set.

\subsection{Modelling the newly-reconnected field lines}

To confirm that our scenario is at all physically consistent, or even possible, we have tested it with two numerical models.

We have first used the Cooling model (Cooling et al., 2001). This model works out, for given interplanetary and solar wind conditions, and for a given location of the X-line, the evolution of new opened field lines (if reconnection is 

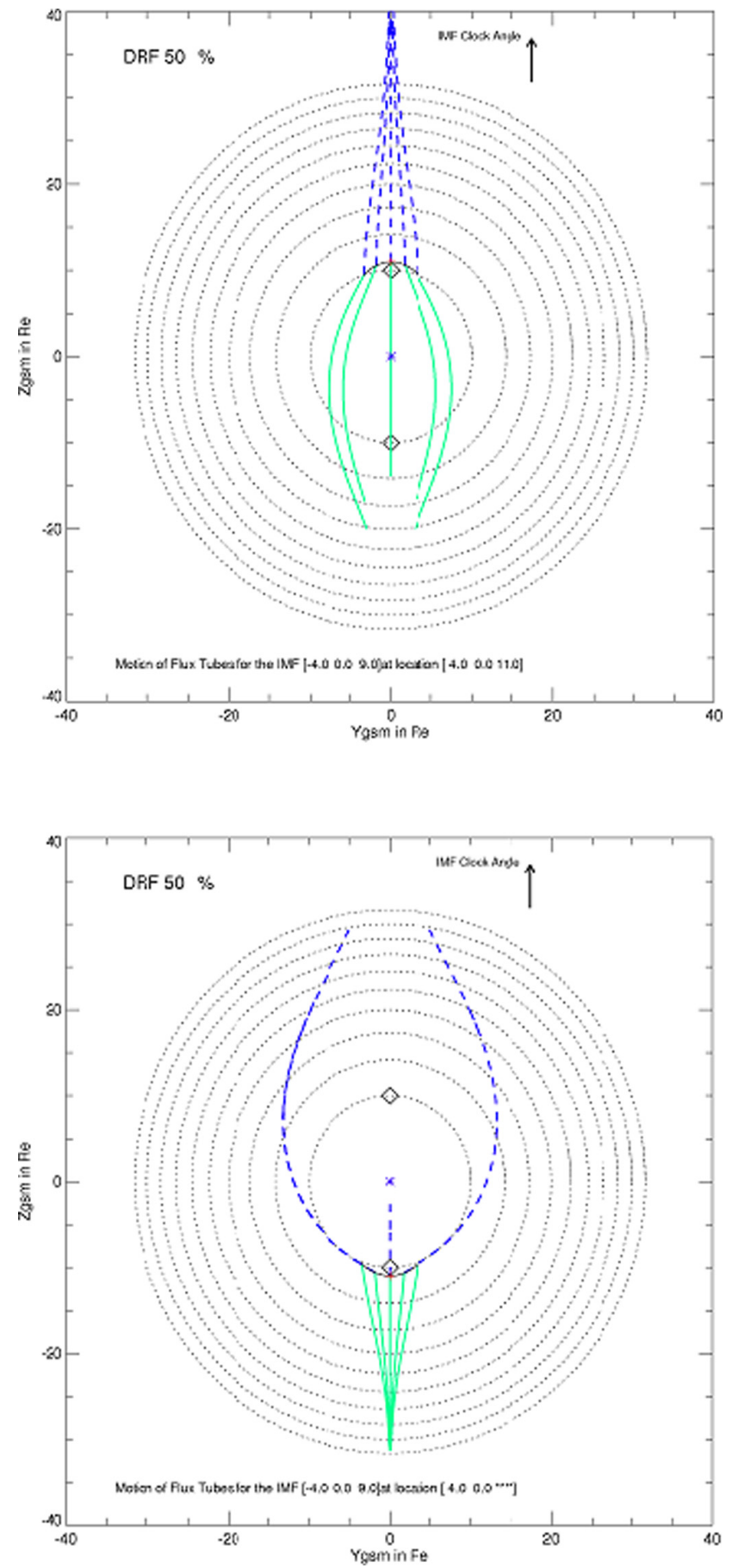

Fig. 9. Output of the Cooling model for a IMF of $(-4,0,9) n T$ in GSM, corresponding to the prevailing IMF when SC3 crosses the cusp, and for a reconnection site poleward of the northern cusp (top) and poleward of the southern cusp (bottom). The blue dashed and green solid lines show the path of newly-reconnected field lines from the X-line (black solid lines).

likely to occur). Fear et al. (2007) made a systematic comparison between the model and many FTEs and found a good

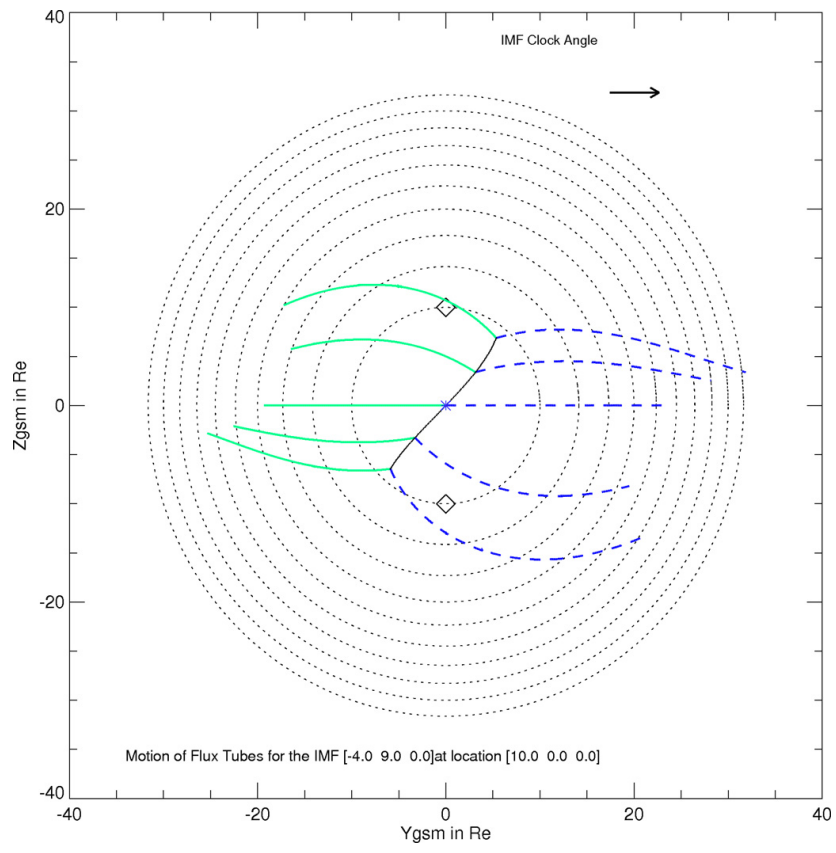

Fig. 10. Output of the Cooling model corresponding to the late observation of SC3 after 08:00 UT when the IMF is dominated by $B_{\mathrm{y}}$. The blue dashed and green solid lines show the path of newlyreconnected field lines from the X-line (black solid lines).

agreement. We can thus use the model with confidence to verify first that reconnection in the lobe was possible under the prevailing IMF conditions and second to make sure that new reconnected field lines would evolve in a way consistent with our interpretation. We have run the model several times for three IMF conditions corresponding to the cusp crossing of $\mathrm{SC} 1$ and two stages of the $\mathrm{SC} 3$ crossing. Figure 8 shows the results of what we expect for SC1. In each panel, an X-line has been chosen poleward of the cusp and the IMF used as an input is $(0,-5,+9) \mathrm{nT}$ in GSM. The magnetosphere is seen from the Sun, dotted circles are isocontours of geocentric distance on the magnetopause, and stars are the two cusps. The short solid lines are the X-lines and the dashed blue and green lines are the path of newlyreconnected field line northward and southward respectively. One can see that once reconnected, the field lines have a strong East-West component, which is compatible with a non-zero Y-component of the IMF. One should note that reconnected field lines in the northern lobe are fast pulled on the sides, which seems hardly compatible with a subsequent reconnection in the Southern Hemisphere to form a reclosed field line. It clearly appears that if dual lobe reconnection occurs, it has to be a field line reconnected in the Southern Hemisphere first that connects then to the Northern Hemisphere.

To model the prevailing conditions when SC 3 crosses the cusp, two locations of the X-line have been chosen poleward of the northern cusp $(4,0,+11) R_{\mathrm{E}}$ and poleward of 


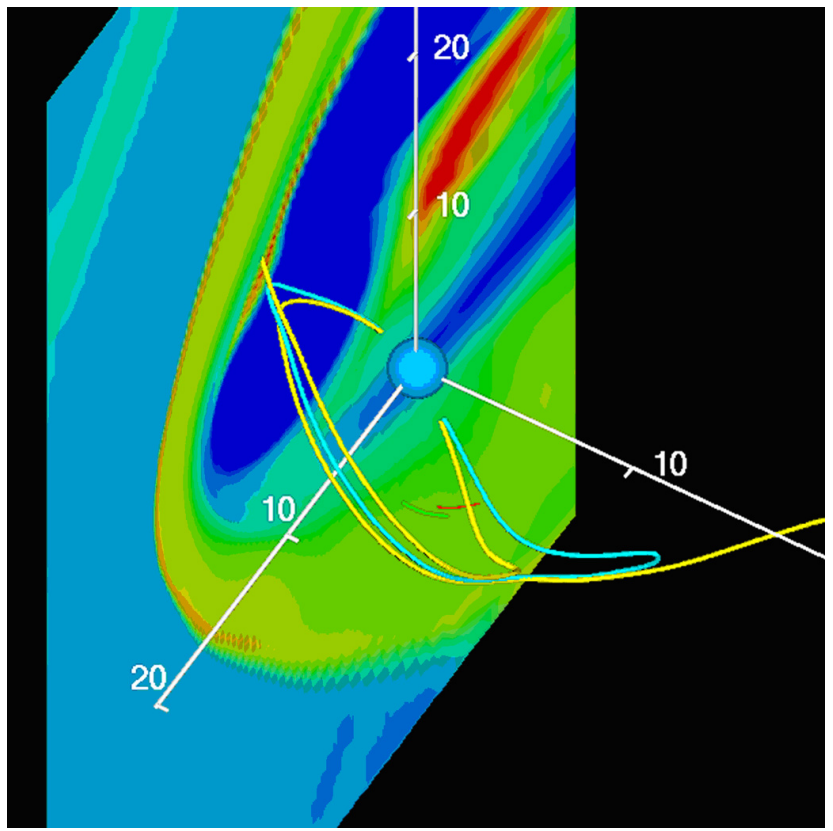

Fig. 11. Results from the MHD model showing a few magnetic field lines (yellow: open; blue: closed) and an arbitrary colour code for the plasma beta (shown in a $\mathrm{x}, \mathrm{z}$ plane).

the southern cusp $(4,0,-11) R_{\mathrm{E}}$ in GSM. The IMF was set to $(-4,0,9) \mathrm{nT}$ in GSM, which corresponds to the IMF conditions prevailing when the two overlapping populations are the most clearly observed by SC3, i.e. around 07:52 UT. Figure 9 shows the results. In both cases, not only is reconnection likely to occur but the newly-reconnected field lines evolve towards the equator, which makes possible, and likely, their re-reconnection in the opposite hemisphere. It is however more difficult to conclude on whether reconnection occurs first in the Northern Hemisphere or Southern Hemisphere. Indeed, we can see in the bottom panel of Fig. 9 that once reconnected in the Southern Hemisphere, field lines are deflected around the magnetosphere, which a priori does not favour re-reconnection in the opposite hemisphere but there seem to be a few field lines reconnected in the Southern Hemisphere first that able to reach the Northern Hemisphere. Particle (both ions and electrons) data suggest that reconnection occurs first in the Southern Hemisphere.

The last stage of SC3 observations (08:00-08:07 UT) is modelled in Fig. 10. The prevailing IMF is then $(-4,9,0) \mathrm{nT}$ in GSM. An X-line may then cross the dayside magnetopause and newly-open field lines move towards the flanks of the magnetosphere. In the Southern Hemisphere cusp, where the Cluster satellites are located, the convection is predicted to be westward (duskward); that is exactly what Cluster observes after 08:00 UT (second panel of Fig. 5). Besides, this field line motion relative to the spacecraft could explain the absence of dispersion in the ion data.

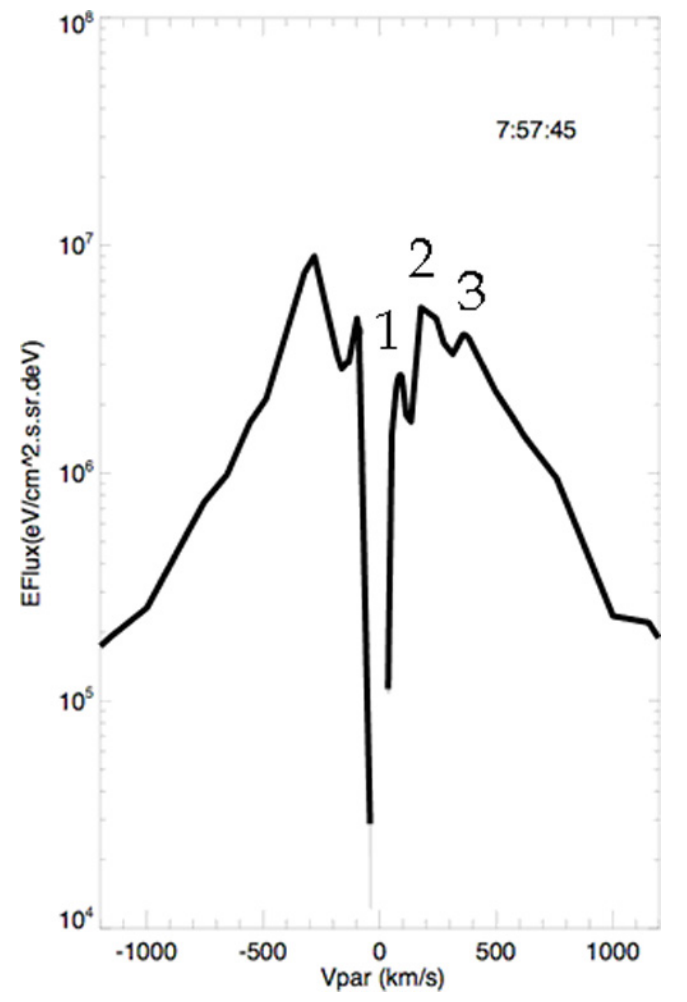

Fig. 12. Cut parallel to the magnetic field through the distribution function recorded by CIS-HIA on board SC3 at 07:57:45 UT.

Results from a global MHD simulation (e.g. Berchem et al., 2008) of the event are displayed in Fig. 11. Solar wind plasma parameters and IMF measured by the ACE spacecraft on 3 September 2002 were used as input to the simulation. Figure 11 shows a three-dimensional view of the field line topology predicted by the simulation for time 07:30 UT. The dayside magnetosphere is viewed from 03:00 LT and a few $R_{\mathrm{E}}$ above the equatorial plane. The GSE coordinate system is used and the orbits of the $\mathrm{C} 1$ and $\mathrm{C} 3$ spacecraft during the 06:00-07:30 UT time interval are represented by the green and red thin traces respectively. Colour contours of plasma beta $(0.1-10)$ in a X-Z cut taken at $y=-5 R_{\mathrm{E}}$, are shown. The plasmasheet and the northern magnetotail lobe are readily associated with the regions of high (red contours) and low-beta plasma (deep blue contours), respectively. The magnetosheath is also clearly bounded by the low beta solar wind (turquoise contours) and the magnetopause (transition between deep blue and green contours). The high-beta layer revealed by red contours at the high-latitude magnetopause indicates that magnetic reconnection is occurring in that region. A set of open field lines (yellow lines) from each hemisphere has been traced. They confirm that highlatitude reconnection is occurring in both hemispheres and that some closed field lines as the one shown by the blue line, are formed on the dayside by dual lobe reconnection. 


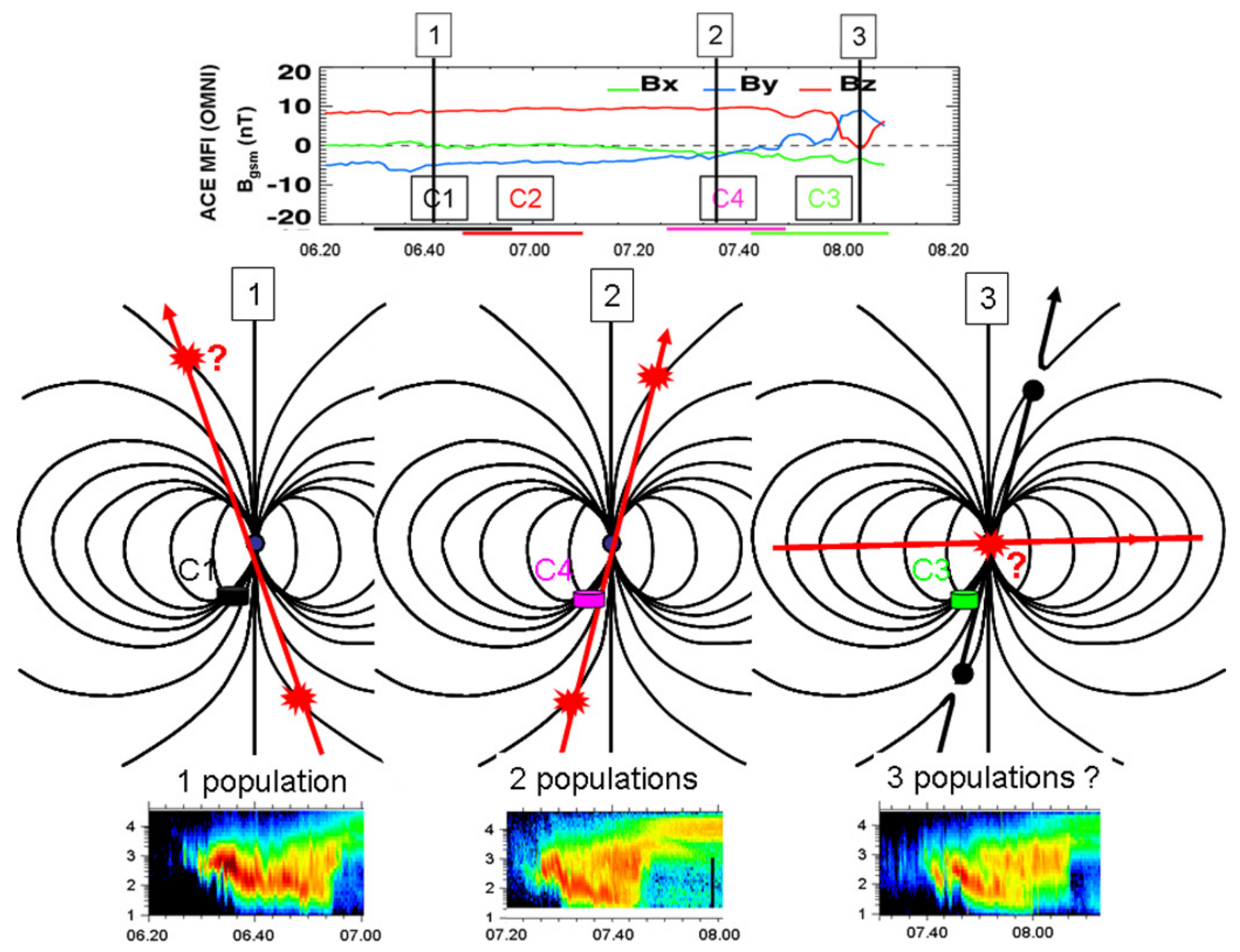

Fig. 13. The top panel shows the lagged magnetic field data recorded by ACE (labels indicate the three successive stages discussed). Below is a schematic for each of the three steps showing the magnetosphere seen from the sun with possible reconnection sites in red. Black lines are magnetospheric field lines and red lines represent IMF lines. At the bottom are the corresponding Cluster-CIS spectrograms.

\subsection{A third population}

As mentioned in Sect. 2.3, this time interval is seen in electron data as a region where magnetosheath electron have been injected (higher fluxes of precipitating electrons, energy dispersion). This injection is likely due to the low value of the IMF $B_{\mathrm{Z}}$ and large value of $B_{\mathrm{y}}$ that may allow for (component) dayside reconnection to occur. This is somewhat supported by ion data that show a less dense region $\left(\sim 15 \mathrm{~cm}^{-3}\right)$ of $\mathrm{keV}$ ion showing no energy dispersion. Also, the plasma convection during this injection is mainly duskward, which is in agreement with the Cooling model for this interval with component dayside reconnection. Figure 12 shows a cut parallel to the magnetic field through the ion distribution function measured at 07:57:47 UT onboard SC3. In the positive parallel velocity domain (up-going ions), the curve exhibits 3 distinct bumps corresponding assumably to 3 different ion populations (tagged 1, 2, and 3). Although not seen has injected particles, this third population corresponds well to the signature of injected electrons seen in PEACE data.

\subsection{Evolution of the cusp, a possible scenario}

The top panel of Fig. 1 shows that the IMF changes during our observations and we obviously need to take these changes into account. Three steps seem to have occurred, which are depicted in Fig. 13. The figure shows on top the three components of the IMF recorded by ACE and just below, the magnetosphere seen from the sun for the three stages. At the bottom, a Cluster ion spectrogram is shown for each of the three steps.

Step 1: in SC1 data at 06:40 UT, only one reversed dispersion is observed, which is the case when lobe reconnection in the Southern Hemisphere occurs. Double reconnection is 
either not operating or not exactly at the local time of the spacecraft due to a negative $B_{\mathrm{y}}(-5 \mathrm{nT})$.

Step 2: by the time $\mathrm{SC} 4$ reaches the cusp and records two populations at 07:40 UT, the IMF $B_{\mathrm{y}}$ decreases in intensity and reaches a value of $\sim 0$ while $B_{\mathrm{z}}$ remains positive. This less oblique northward IMF is supposed to favour double reconnection (Reiff and Burch, 1985) and indeed, SC4 records two overlapping populations. However, it is not quite clear whether reconnection occurs in both hemispheres simultaneously.

Step 3: around 07:45 UT, while SC3 is crossing the cusp, $B_{\mathrm{Z}}$ is almost 0 and $B_{\mathrm{y}}$ still increases to reach the value of $+9 \mathrm{nT}$. A third ion population appears at $\sim \mathrm{keV}$ energy. This population may come from component reconnection at the dayside magnetopause made possible by a clock angle close to $90^{\circ}$ or diffusive entry of magnetosheath plasma through the magnetopause. Both these processes would lead to a third population on newly-open field lines. However, the fact that this third population appears after the $B_{\mathrm{y}}$ and $B_{\mathrm{z}}$ changes and not before when the IMF was stable for more than an hour favours magnetic reconnection. In addition, there are clear indications in the electron data from the appearance of a LLBL that dayside reconnection has re-initiated.

\section{Summary}

We have reported on three successive crossings of the midaltitude cusp by the Cluster spacecraft in the Southern Hemisphere. While the IMF was pointing northward, we observed overlapping ion populations in the mid-altitude southern cusp, near its equatorward boundary. These ion populations, obviously of magnetosheath origin, exhibit reverse dispersions. In addition, we observe the presence of bidirectionnal electrons with similar fluxes in the parallel and anti-parallel directions, possibly indicative of closed field lines.

The most plausible interpretation of this overlapping is the dual occurrence of magnetic reconnection between the IMF and two magnetospheric lobe field lines, leading to the formation of newly-closed field lines. We have run the Cooling model and a MHD model that both substantiate this interpretation. Conditions for having such double reconnection seem to be, in our case at least, related to the geometry of the IMF (weak $B_{\mathrm{x}}$ and $B_{\mathrm{y}}$ ). A third population is observed by C3 when IMF- $B_{\mathrm{y}}$ becomes dominant. This third population seems to be related to component dayside reconnection starting under a $B_{\mathrm{y}}$-dominated IMF as our data and modelling suggest it.

Acknowledgements. We would like to thank I. Dandouras for helpful discussion. The OMNI data were obtained from the GSFC/SPDF OMNIWeb interface at http://omniweb.gsfc.nasa.gov.

Guest Editor A. Masson thanks Y. Bogdanova and another anonymous referee for their help in evaluating this paper.

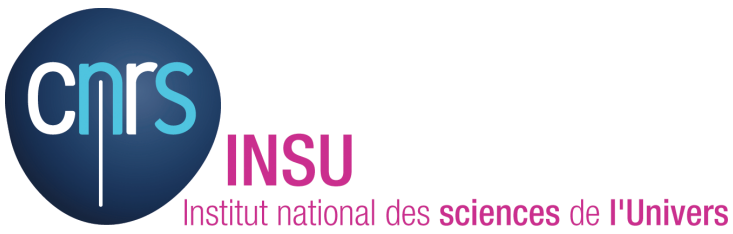

The publication of this article is financed by CNRS-INSU.

\section{References}

Berchem, J., Marchaudon, A., Dunlop, M., Escoubet, C. P., Bosqued, J. M., Reme, H., Dandouras, I., Balogh, A., Lucek, E., Carr, C., and Pu, Z.: Reconnection at the dayside magnetopause: Comparisons of global MHD simulation results with Cluster and Double Star observations, J. Geophys. Res., 113, A07S12, doi:10.1029/2007JA012743, 2008.

Bogdanova, Y. V., Marchaudon, A., Owen, C. J., Dunlop, M. W., Frey, H. U., Wild, J. A., Fazakerley, A. N., Klecker, B., Davies, J. A., and Milan, S. E.: On the formation of the high-altitude stagnant cusp: Cluster observations, Geophys. Res. Lett., 32, L12101, doi:10.1029/2005GL022813, 2005.

Bogdanova, Y. V., Owen, C. J., Dunlop, M. W., Wild, J. A., Davies, J. A., Lahiff, A. D., Taylor, M. G. G. T., Fazakerley, A. N., Dandouras, I., Carr, C. M., Lucek, E. A., and Reme, H.: Formation of the low-latitude boundary layer and cusp under the northward IMF: Simultaneous observations by Cluster and Double Star, J. Geophys. Res., 113, A07S07, doi:10.1029/2007JA012762, 2008.

Bosqued, J.-M., Sauvaud, J. A., Rème, H., Crasnier, J., Galperin, Yu. I., Kovrazhkin, R. A., and Gladyshev, V. A.: Evidence for ion energy dispersion in the polar cusp related to a northwarddirected IMF, Adv. Space Res., 5, 149-153, doi:10.1016/02731177(85)90130-9, 1985.

Burch, J. L., Reiff, P. H., Spiro, R. W., Heelis, R. A., and Fields, S. A.: Cusp region particle precipitation and ion convection for northward interplanetary magnetic field, Geophys. Res. Lett., 7, 393-396, 1980.

Burch, J. L., Reiff, P. H., Heelis, R. A., Winningham, J. D., Hanson, W. B., Gurgiolo, C., Menietti, J. D., Hoffman, R. A., and Barfield, J. N.: Plasma injection and transport in the mid-altitude polar cusp, Geophys. Res. Lett., 9, 921-924, 1982.

Cooling, B. M. A., Owen, C. J., and Schwartz, S. J.: Role of the magnetosheath flow in determining the motion of open flux tubes, J. Geophys. Res., 106, 18763-18775, doi:10.1029/2000JA000455, 2001.

Cowley, S. W. H.: Magnetospheric and ionospheric flow and the interplanetary magnetic field, n AGARD The Phys, Basis of the Ionosphere in the Solar-Terrest. System, 14 p., see N81-23507 14-42, 1981.

Dungey, J. W.: The structure of the exosphere or adventures in velocity space, in: Geophysics, The Earth's Environment, edited by: DeWitt, C., Hieblot, J., and Leneau, A., pp. 505, Gordon Breach, New York, 1963.

Escoubet, C. P., Fehringer, M., and Goldstein, M.: Introduction: The Cluster mission, Ann. Geophys., 19, 1197-1200, doi:10.5194/angeo-19-1197-2001, 2001.

Fear, R. C., Milan, S. E., Fazakerley, A. N., Owen, C. J., Asikainen, T., Taylor, M. G. G. T., Lucek, E. A., Rème, H., Dandouras, I., and Daly, P. W.: Motion of flux transfer events: a test of the Cool- 
ing model, Ann. Geophys., 25, 1669-1690, doi:10.5194/angeo25-1669-2007, 2007.

Fuselier, S. A., Anderson, B. J., and Onsager, T. G.: Electron and ion signatures of field line topology at the lowshear magnetopause, J. Geophys. Res., 102, 4847-4863, doi:10.1029/96JA03635, 1997.

Fuselier, S. A., Petrinec, S. M., Trattner, K. J., and Peterson, W. K.: $\mathrm{O}+$ observations in the cusp: Implications for dayside magnetic field topology, J. Geophys. Res., 106, 5977-5986, 2001.

Hu, R., Bogdanova, Y. V., Owen, C. J., Foullon, C., Fazakerley, A. N., and Reme, H.: Cluster observations of the mid-altitude cusp under strong northward interplanetary magnetic field, J. Geophys. Res., 113, A07S05, doi:10.1029/2007JA012726, 2008.

Imber, S. M., Milan, S. E., and Hubert, B.: The auroral and ionospheric flow signatures of dual lobe reconnection, Ann. Geophys., 24, 3115-3129, doi:10.5194/angeo-24-3115-2006, 2006.

Johnstone, A. D., Alsop, C., Burge, S., Carter, P. J., Coates, A. J., Coker, A. J., Fazakerley, A. N., Grande, M., Gowen, R. A., Gurgiolo, C., Hancock, B. K., Narheim, B., Preece, A., Sheather, P. H., Winningham, J. D., and Woodliffe, R. D.: Peace: A Plasma Electron and Current Experiment, Space Sci. Rev., 79, 351-398, 1997.

Lavraud, B., Thomsen, M. F., Lefebvre, B., Schwartz, S. J., Seki, K., Phan, T. D., Wang, Y. L., Fazakerley, A., Rème, H., and Balogh, A.: Evidence for newly-closed magnetosheath field lines at the dayside magnetopause under northward IMF, J. Geophys. Res., 111, A05211, doi:10.1029/2005JA011266, 2006.

Lockwood, M.: Overlapping cusp ion injections: an explanation invoking magnetopause reconnection, Geophys. Res. Lett., 22, 1141-1144, 1995.

Lockwood, M.: Energy and pitch-angle dispersions of LLBL/cusp ions seen at middle altitudes: predictions by the open magnetosphere model, Ann. Geophys., 15, 1501-1514, doi:10.1007/s00585-997-1501-4, 1997.

Lockwood, M. and Moen, J.: Reconfiguration and closure of lobe flux by reconnection during northward IMF: possible evidence for signatures in cusp/cleft auroral emissions, Ann. Geophys., 17, 996-1011, doi:10.1007/s00585-999-0996-2, 1999.

Lockwood, M. and Smith, M. F.: Low and Middle Altitude Cusp Particle Signatures for General Magnetopause Reconnection Rate Variations: 1. Theory, J. Geophys. Res., 99, 85318553, doi:10.1029/93JA03399, 1994.

Onsager, T. G., Scudder, J. D., Lockwood, M., and Russell, C. T.: Reconnection at the high-latitude magnetopause during northward interplanetary magnetic field conditions, J. Geophys. Res., 106, 25467-25488, doi:10.1029/2000JA000444, 2001.

Phan, T.-D., Oieroset, M., and Fujimoto, M.: Reconnection at the dayside low-latitude magnetopause and its nonrole in low-latitude boundary layer formation during northward interplanetary magnetic field, Geophys. Res. Lett., 32, L17101, doi:10.1029/2005GL023355, 2005.

Pitout, F., Escoubet, C. P., Klecker, B., and Dandouras, I.: Cluster survey of the mid-altitude cusp - Part 2: Large-scale morphology, Ann. Geophys., 27, 1875-1886, doi:10.5194/angeo-271875-2009, 2009.

Provan, G., Lester, M., Grocott, A., and Cowley, S. W. H.: Pulsed flows observed during an interval of prolonged northward IMF, Ann. Geophys., 23, 1207-1225, doi:10.5194/angeo-23-1207$2005,2005$.
Reiff, P. H. and Burch, J. L.: IMF By-Dependent Plasma Flow and Birkeland Currents in the Dayside Magnetosphere, 2. A Global Model for Northward and Southward IMF, J. Geophys. Res., 90, 1595-1609, 1985.

Reiff, P. H., Hill, T. W., and Burch, J. L.: Solar Wind Plasma Injection at the Dayside Magnetospheric Cusp, J. Geophys. Res., 82, 479-491, 1977.

Rème, H., Aoustin, C., Bosqued, J. M., Dandouras, I., Lavraud, B., Sauvaud, J. A., Barthe, A., Bouyssou, J., Camus, Th., CoeurJoly, O., Cros, A., Cuvilo, J., Ducay, F., Garbarowitz, Y., Medale, J. L., Penou, E., Perrier, H., Romefort, D., Rouzaud, J., Vallat, C., Alcaydé, D., Jacquey, C., Mazelle, C., d'Uston, C., Möbius, E., Kistler, L. M., Crocker, K., Granoff, M., Mouikis, C., Popecki, M., Vosbury, M., Klecker, B., Hovestadt, D., Kucharek, H., Kuenneth, E., Paschmann, G., Scholer, M., Sckopke, N., Seidenschwang, E., Carlson, C. W., Curtis, D. W., Ingraham, C., Lin, R. P., McFadden, J. P., Parks, G. K., Phan, T., Formisano, V., Amata, E., Bavassano-Cattaneo, M. B., Baldetti, P., Bruno, R., Chionchio, G., Di Lellis, A., Marcucci, M. F., Pallocchia, G., Korth, A., Daly, P. W., Graeve, B., Rosenbauer, H., Vasyliunas, V., McCarthy, M., Wilber, M., Eliasson, L., Lundin, R., Olsen, S., Shelley, E. G., Fuselier, S., Ghielmetti, A. G., Lennartsson, W., Escoubet, C. P., Balsiger, H., Friedel, R., Cao, J.-B., Kovrazhkin, R. A., Papamastorakis, I., Pellat, R., Scudder, J., and Sonnerup, B.: First multispacecraft ion measurements in and near the Earth's magnetosphere with the identical Cluster ion spectrometry (CIS) experiment, Ann. Geophys., 19, 1303-1354, doi:10.5194/angeo19-1303-2001, 2001

Rosenbauer, H., Grünwaldt, H., Montgomery, M. D., Paschmann, G., and Sckopke, N.: Heos 2 Plasma Observations in the Distant Polar Magnetosphere: The Plasma Mantle, J. Geophys. Res., 80, 2723-2737, doi:10.1029/JA080i019p02723, 1975.

Smith, C. W., Acuna, M. H., Burlaga, L. F., L’Heureux, J., Ness, N. F., and Scheifele, J.: The ACE Magnetic Fields Experiment, Space Sci. Rev., 86, 613-632, 1998.

Song, P. and Russell, C. T.: Model of the formation of the lowlatitude boundary layer for strongly northward interplanetary magnetic field, J. Geophys. Res., 97, 1411-1420, 1992.

Stone, E. C., Frandsen, A. M., Mewaldt, R. A., Christian, E. R., Margolies, D., Ormes, J. F., and Snow, F.: The Advanced Composition Explorer, Space Sci. Rev., 86, 1-22, 1998.

Topliss, S. M., Owen, C. J., and Peterson, W. K.: A Simple Model of Complex Cusp Ion Dispersions during Intervals of Northward Interplanetary Magnetic Field, Geophys. Res. Lett., 27, 35873590, 2000.

Trattner, K. J., Coates, A. J., Fazakerley, A. N., Johnstone, A. D., Balsinger, H., Burch, J. L., Fuselier, S. A., Peterson, W. K., Rosenbauer, H., and Shelley, E. G.: Overlapping ion populations in the cusp: Polar/TIMAS results, Geophys. Res. Lett., 25, 16211624, 1998.

Xue, S., Reiff, P. H., and Onsager, T. G.: Mid-altitude modeling of cusp ion injection under steady and varying conditions, Geophys. Res. Lett., 24, 2275-2278, 1997.

Yamauchi, M. and Lundin, R.: Classification of large-scale and meso-scale ion dispersion patterns observed by Viking over the cusp-mantle region, in: Physical Signatures of Magnetospheric Boundary Layer Process, edited by: Holtet, J. A. and Egeland, A., pp. 99-109, Kluwer Academic Publishers, Dordrecht, Netherlands, 1994. 